\title{
ЭКСПРЕССИЯ ХИМЕРНОГО АНТИГЕННОГО РЕЦЕПТОРА В НАТУРАЛЬНЫХ КИЛЛЕРАХ ЛИНИИ NК-92 ПУТЕМ ТРАНСДУКЦИИ ЛЕНТИВИРУСНЫМИ ЧАСТИЦАМИ, ПСЕВДОТИПИРОВАННЫМИ ПОВЕРХНОСТНЫМИ ГЛИКОПРОТЕИНАМИ ВАКЦИННОГО ШТАММА ВИРУСА КОРИ
}

\author{
Ю. Е. Кравченко, Д. И. Гагаринская, Е. И. Фролова, С. П. Чумаков $ه$
}

Институт биоорганической химии имени М. М. Шемякина и Ю. А. Овчинникова РАН, Москва

\begin{abstract}
Клеточная иммунотерапия с использованием химерных антигенных рецепторов (XAP) является одним из перспективных направлений развития современной онкологии. Собственные Т-лимфоциты пациента с приданной специфичностью в отношении неоантигенов опухолей за счет экспрессии ХАР демонстрируют клиническую эффективность, однако стоимость такой терапии чрезвычайно высока. В качестве более доступной альтернативы могут быть использованы унифицированные носители ХАР на основе линии клеток натуральных киллеров NK-92. Эта культура отличается устойчивостью к лентивирусной трансдукции; однако для трансдукции первичных иммунных клеток недавно начали успешно применять лентивирусные векторы, псевдотипированные поверхностными гликопротеинами вакцинного штамма вируса кори. Целью работы было определить эффективность трансдукции клеток NK-92 лентивирусами, псевдотипированными гликопротеинами F и H вируса кори, а также условия селекции NK-92, трансдуцированных химерным рецептором против CD20, и оценить их цитотоксическое действие. Результаты исследования показали, что максимальный трансфекционный титр достигается при использовании варианта белка $\mathrm{H}(\mathrm{H} \triangle 18)$ в сочетании с вариантом белка F (F $\triangle 30)$, а применение BX795 (ингибитора TBK1/IKKع) дополнительно позволяет добиться трехкратного увеличения инфекционного титра. ХАР-экспрессирующие клетки NK-92 оказались способными подавлять пролиферацию CD20+-клеток линии Rаjі в меньшей дозе, по сравнению с немодифицированными клетками NK-92.
\end{abstract}

Ключевые слова: клеточная иммунотерапия, химерные антигенные рецепторы, ХАР, лентивирусные векторы, натуральные киллеры, линейные клеточные носители, псевдотипирование, гликопротеины кори

Финансирование: работа выполнена при финансовой поддержке Министерства образования и науки РФ, уникальный код проекта RFMEFI60716X0156.

$\checkmark$ Для корреспонденции: Степан Петрович Чумаков

ул. Миклухо-Маклая, 16/10, г. Москва, 117997; hathkul@gmail.com

Статья получена: 27.11.2018 Статья принята к печати: 20.12.2018

DOI: $10.24075 /$ vrgmu.2018.091

\section{CHIMERIC ANTIGEN RECEPTOR EXPRESSION IN NATURAL KILLER CELL LINE NK-92 BY TRANSDUCTION WITH LENTIVIRAL PARTICLES PSEUDOTYPED WITH THE SURFACE GLYCOPROTEINS OF THE MEASLES VIRUS VACCINE STRAIN}

\author{
Kravchenko YE, Gagarinskaya DI, Frolova El, Chumakov SP $\square$ \\ Shemyakin-Ovchinnikov Institute of Bioorganic Chemistry of the Russian Academy of Sciences, Moscow
}

Cancer immunotherapy with T-cells that carry chimeric antigen receptors is currently on cutting edge of modern oncology. Autotransplantation of T-lymphocytes with chimeric receptor specific for certain tumor antigen proves to be clinically effective, but costly. Linear carriers of chimeric antigen receptors based on natural killer NK-92 cell culture may be an affordable alternative, however, this culture is resistant to lentiviral transduction. Recently, lentiviral vectors, pseudotyped with surface glycoproteins of the measles virus vaccine strain, have recently been successfully applied for transduction of primary immune cells. The aim of the work was to assess the efficiency of transduction of NK-92 cells with lentivirus vectors, pseudotyped with measles $\mathrm{F}$ and $\mathrm{H}$ surface glycoproteins, as well as to establish optimal conditions for selection of NK-92 transduced with the chimeric receptor against CD20 and to evaluate the culture's cytotoxic potential. The results showed that the maximum infectious titer is achieved using the $\mathrm{H} \triangle 18$ variant in combination with $\mathrm{F} \triangle 30$, and the use of the TBK1/IKKE inhibitor BX795 results in additional 3 -fold increase in the infectious titer. CAR-expressing NK-92 were able to suppress the proliferation of CD20 ${ }^{+}$cell line Raji in lower effector-to-target ratios than unmodified NK-92.

Keywords: cellular immunotherapy, chimeric antigen receptors, CAR, lentiviral vectors, natural killer cells, linear cellular carriers, pseudotyping with measles glycoproteins

Funding: this work was funded by MESR (project code RFMEFI60716X0156).

$\triangle$ Correspondence should be addressed: Stepan P. Chumakov Miklukho-Maklaya 16/10, Moscow, 117997; hathkul@gmail.com Received: 27.11.2018 Accepted: 20.12.2018

DOI: 10.24075/brsmu.2018.091 
Совершенствование методов клеточной иммунотерапии для борьбы со злокачественными новообразованиями является одним из ключевых направлений развития современной онкологии. Введение в организм иммунных клеток, нацеленных на опухолевые антигены, позволяет добиться высокой специсичности действия и эффективности лечения при низкой частоте развития нежелательных эффектов [1]. В исследовательских работах и при клинических испытаниях часто используют собственные цитотоксические Т-лимфоциты пациента которым искусственно придается специфичность в отношении определенного опухолевого антигена или их комбинации. Подобные модификации осуществляют за счет экспрессии химерного антигенного рецептора (ХАР), состоящего из нескольких внутриклеточных сигнальных доменов для активации Т-лимфоцита, и внеклеточного участка, распознающего опухолевый антиген [2]. Для введения конструкций, экспрессирующих ХАР, применяют химическую трансфекцию клеток [3], электропорацию [4] или трансдукцию вирусными векторами [5]. После трансдукции клеточная популяция может быть пассирована в культуре для получения необходимого количества клеток. Препараты ХАР-Т-клеток демонстрируют неплохую клиническую эффективность, однако стоимость терапии с их использованием чрезвычайно высока, что объясняется необходимостью производства персонализированной популяции Т-клеток для каждого пациента. Другой причиной невозможности массового применения ХАР-Тклеток служит ограниченная доступность собственных Т-лимфоцитов у тяжелых онкологических больных. Преодолеть эти барьеры можно, но это потребует существенного совершенствования технологий получения клеточных препаратов.

В качестве менее дорогой и более доступной альтернативы ХАР-Т-клеточным препаратам могут быть использованы унифицированные носители ХАР - линии клеток натуральных киллеров. Из 11 установленных и широко доступных линий натуральных киллеров, полученных от пациентов с различными лимфопролиферативными заболеваниями, только две - KHYG-1 [6] и NK-92 [7] обладают выраженной способностью подавлять рост опухолевых клеток за счет цитотоксического действия, при отсутствии экспрессии на своей поверхности Т-клеточных рецепторов [8]. Обе клеточные линии способны пролиферировать в присутствии IL2 в культуральной среде, а для NK-92 была показана способность избирательно уничтожать клетки лимфомы линии К-562, культивируемые в смеси с нормальными периферическими мононуклеарными клетками. Клетки линии NK-92 также оказались способными сохранять цитотоксичность после $\gamma$-облучения дозой 10 Гр при утрате способности к пролиферации, что позволяет использовать их для терапии онкологических заболеваний [9].

Для усиления цитотоксических свойств NK-92 были созданы генетически модифицированные варианты, экспрессирующие собственные IL2, IL15 [10]; или дополнительные рецепторы CD16 для нацеливания на опухолевые клетки при помощи антител, либо ХАР для прямого распознавания опухолевых антигенов [11]. Функционально ХАР-экспрессирующие NK-92 аналогичны ХАР-Т-клеткам, при этом стоимость терапии может быть значительно ниже, так как линейные клетки можно культивировать в промышленных масштабах, а подготовительные процедуры для лечения пациента будут заключаться лишь в размораживании ампулы готового препарата [12]. Помимо использования для терапии, клетки NK-92 могут служить в качестве клеточной платформы для тестирования различных вариантов химерных рецепторов in vitro $n$ in vivo. Основное препятствие при работе с клетками этой линии заключается в их чувствительности к условиям культивации, а также высокой устойчивости к лентивирусной трансдукции: вирусные векторы, псевдотипированные G-белком вируса везикулярного стоматита (VSV), неэффективно заражают клетки NK-92, а при повышении количества вирусных частиц в среде клетки теряют жизнеспособность [13]. Для проведения лентивирусной трансдукции периферических Т-лимфоцитов и иммунных клеток миелоидного ряда не так давно были испытаны лентивирусные векторные частицы, псевдотипированные поверхностными гликопротеинами вакцинного штамма вируса кори [14]. Было показано, что по сравнению с обычными лентивирусными векторами, псевдотипированными белком G вируса везикулярного стоматита, они обладают более высокой способностью трансдуцировать иммунные клетки, не вызывая при этом стимулирования клеточных делений, смены фенотипа и изменения профиля секретируемых цитокинов [15]. Целью настоящей работы было определить эфффективность трансдукции клеток NK-92 лентивирусами, псевдотипированными гликопротеинами $\mathrm{F}$ и $\mathrm{H}$ вируса кори, определить условия выделения и очистки клеток NK-92, трансдуцированных химерным рецептором, направленным против антигена CD20, а также оценить их цитотоксический потенциал.

\section{МАТЕРИАЛЫ И МЕТОДЫ}

\section{Плазмиды и конструкции}

Для упаковки лентивирусных векторов, псевдотипированных VSV-G, использовали упаковочные плазмиды psPAX2 (содержит структурные белки лентивируса) и pMD2-G (кодирует G-белок вируса везикулярного стоматита). Обе плазмиды были любезно предоставлены Дидьером Троно (Addgene plasmid \# 12260; http://n2t.net/addgene:12260; RRID:Addgene_12260 и Addgene plasmid \#12259; http:// n2t.net/addgene:12259; RRID:Addgene_12259). Для псевдотипирования гликопротеинами кори, вместо pMD2-G использовали плазмиду pMD2-F $\Delta 30$, кодирующую фрагмент F-белка вируса кори вакцинного штамма ЭШЧ с укороченным на 30 аминокислот цитоплазматическим доменом. Для ревертирования РНК вируса кори и амплификации целевого фрагмента генома применяли праймеры Fdelta30 dir EcoRI (AGAGGAATTCACCACCATGTCC ATCATGGGTCTCAAGGTGAACGTCTCTG) и Fdelta30 rev EcoRl (AGAGAGAATTCTCAACGCCCCCTGCAGCAACATATTAAAG CG), клонирование производили в вектор pMD2-G по сайтам EcoRl. B сочетании с pMD2-FA30 была использована плазмида pCG-Hc 18 , предоставленная Джейкобом Рейзером (Addgene plasmid \# 84817; http://n2t.net/addgene:84817; RRID:Addgene_84817), а также ее варианты, в которых делетированы 24 N-концевых аминокислоты H-белка (pCG$\mathrm{Hc} \Delta 24)$, либо содержащие перед укороченным Н-белком дополнительные 4 аминокислотных остатка аланина (pCG4 AHc $\triangle 24)$. Плазмиды были получены путем клонирования в исходный вектор фрагментов Н-белка, амплифицированных с праймерами Hd24 BamHI dir (AGAGAGGGATCCAGGGTG CAAGATCATCCACAATGAACCGGGAGCACCTGATG) $и \mathrm{H}$ rev (CTGATGTCTATTTCACACTAGTACAAAC), либо с праймерами Hd24 4a BamHI dir (AGAGAGGGATCCAGGGTGCAAGATCATC 
CACAATGGCCGCTGCAGCCAACCGGGAGCACCTGATG) и н rev соответственно по сайтам BamHI и Spel. Для отработки условий трансдукции и испытания цитотоксического действия применяли лентивирусные векторы pLCMVtagRFP-puro, который содержит последовательность красного фллуоресцентного белка tagRFP (Евроген; Россия) под контролем цитомегаловирусного промотора, и pLSF-@ CD20-229-tagRFP, содержащий последовательность химерного рецептора третьего поколения против поверхностного антигена CD20 (лидерный пептид CD8, ScFv из гибридомы HB-9645, эпитоп DYKDDDDK, линкерный участок 229 аминокислот, трансмембранный домен CD28 и сигнальные домены CD28, CD137, CD3z) и tagRFP, эКспрессирующиеся полицистронно при помощи сигнальной последовательности Т2А под контролем промотора SFFV.

\section{Культуры клеток}

Для получения препаратов вируса использовали клетки линии НЕK-293Т, которые культивировали в среде DMEM-F12 (РАА; Австрия) с добавлением 10\% эмбриональной сыворотки теленка, 2 мМ аланил-глутамина (ПанЭко; Россия), 20 мМ HEPES и по 100 мкг/мл пенициллина и стрептомицина.

Культивацию NK-92 проводили в питательной среде RPMI-1640 (РAA; Австрия) с добавлением 20\% эмбриональной сыворотки теленка и сыворотки крови лошади в равных пропорциях, 2 мМ аланил-глутамина (ПанЭко; Россия), 20 мМ HEPES, 0,2 мМ инозитола, 0,1 мМ 2-меркаптоэтанола, 1 мкM водорастворимого гидрокортизона (Sigma-Aldrich; США), 20 мкМ фолиевой кислоты и рекомбинантного IL2 в конечной концентрации 100 мкг/Мл.

В качестве мишеней для ХАР-экспрессирующих клеток NK-92 в работе использовали клетки линии Raji (лимфома Беркитта) (АТСС; США), экспрессирующие флуоресцентный белок GFP. Клетки культивировали в среде RPMI-1640 (ПанЭко; Россия) с добавлением 10\% эмбриональной сыворотки теленка, 2 мМ аланилглутамина (ПанЭко; Россия), 20 мМ HEPES и по 100 мкг/ мл пенициллина и стрептомицина. Все клетки содержали в условиях $5 \%-г о \mathrm{CO}_{2}$ при $37^{\circ} \mathrm{C}$.

\section{Трансфекция и вирусная трансдукция}

Трансфекцию проводили на 6-луночных планшетах в среде для культивации OptiMEM (Invitrogen; США) с использованием полиэтиленимина 25кДА (PEI-25, Polysciences; США) на клетках НЕК-293Т в плотности 40-60\% от монослоя, рассеянных накануне.

Для лентивирусных векторов, псевдотипированных VSV-G, была приготовлена смесь из следующих плазмид: pLCMV-tagRFP-puro, содержащей маркерный белок (1,5 мкг), psPAX2 (0,9 мКГ) и pMD2-G (0,6 МкГ) в соотношении $5: 3: 2$ соответственно. Для псевдотипирования гликопротеинами кори использовали плазмиды pLCMV-tagRFP-puro либо pLSF-@CD20-229-tagRFP (0,9 МКг), psPAX2 (0,9мКг), pMD2-F $\triangle 30$ (0,79 мкг), pCG-Hc $\triangle 18$ (0,11 мкг) или еe вариации pCG-Hc $\Delta 24$ (0,11 мкг) и pCG-4AHc $\triangle 24$ (0,11 мкг) в соотношении $8: 8: 7: 1$. После трехчасовой инкубации клеток с трансфекционной смесью среда была заменена на RPMI с содержанием заменителя сыворотки (Serum Replacement Solution, PeproTech; США), 2 мМ аланилглутамина (ПанЭко; Россия), 20 мМ HEPES и 4 мМ кофеина, в которой НЕК-293Т инкубировали в течение 24 ч для наработки вирусного препарата. Вирусную трансдукцию проводили в течение 8-12 ч на клетках NK-92, взятых в количестве не менее $5 \cdot 10^{5}$ в 1 мл. В содержащую вирус среду предварительно добавили полибрен в концентрации 8 мкг/мл и недостающие питательные добавки, входящие в состав среды для культивации клеток NK-92, а также BX795 в концентрации 3 мкМ. Затем среду заменили на обычную для клеток NK-92. Результат трансдукции оценивали через 48 ч. Инфекционный титр вирусных частиц и эффективность трансдукции определяли с помощью проточного цитометра посредством оценки tagRFP-положительной фракции.

\section{Определение цитотоксичности}

Для оценки цитотоксичности клетки NK-92 смешивали с клетками Raji, экспрессирующими GFP, в различных соотношениях. После совместной культивации в течение 48 ч на проточном цитометре оценивали долю и количество GFP-положительных клеток.

\section{РЕЗУЛЬТАТЫ ИССЛЕДОВАНИЯ}

\section{Определение оптимального соотношения упаковочных плазмид}

Для оценки эффективности трансдукции клеток линии NK-92 были использованы препараты лентивирусных частиц, псевдотипированные белком G вируса VSV, либо тремя различными вариантами Н-белка вируса кори в сочетании с F-белком (H/F-псевдотипированные). В литературных источниках приводится противоречивая информация об оптимальном соотношении упаковочных плазмид, приводящем к получению наибольших титров вируса [15-19]. Соотношения, известные из литературы, а также полученные путем экстраполяции применяемых для упаковки VSV-G-псевдотипированных лентивирусных векторов (вектор : psPAX2 : pMD2-G как $5: 3: 2$ ), были использованы для получения препаратов лентивирусов и последующего определения их инфекционного титра (рис. 1). Результаты показали, что соотношения плазмид $8: 8: 7: 1$ и $15: 9: 2: 1$ для векторов pLCMV-tagRFPpuro : psPAX2 : pMD2-Fd30 : pCG-HА18 демонстрировали наиболее эффективную упаковку лентивирусных частиц для варианта белка $\mathrm{H} \triangle 18$. Для всех дальнейших экспериментов было использовано соотношение $8: 8: 7: 1$.

\section{Сравнение вариантов белка Н}

Характерной особенностью псевдотипирования H/Fбелками является образование синцитиев в культуре клеток-упаковщиков. Длина цитоплазматических участков белков H и $\mathrm{F}$ непосредственно влияет на интенсивность этого процесса, и чем менее активно формируются синцитии, тем дольше клетки-упаковщики могут быть использованы для сбора лентивирусных частиц. Избыточное укорачивание цитоплазматических доменов приводит к резкому падению трансфекционного титра. Приводятся данные, что вариант белка Н $\triangle 18$ в сочетании c белком F $\triangle 30$ производит лентивирусные векторные препараты с максимальным транфекционным титром, при этом укорочение до $\mathrm{H} \triangle 24$ практически полностью подавляет продукцию векторного вируса, а добавление четырех аланиновых остатков на N-конец такого мутанта восстанавливает трансфекционный титр до максимальных 
значений [16]. В другой работе использовали вариант белка $\mathrm{H} \triangle 24$ для получения высококонцентрированных лентивирусных препаратов [15]. Результаты проведенного нами сравнения трех вариантов белка Н показали, что размер и скорость образования синцитиев максимальны для варианта белка $\mathrm{H} \Delta 18$, существенно ниже у варианта $4 \mathrm{~A}-\mathrm{H} \triangle 24$ и минимальны у $\mathrm{H} \triangle 24$ (рис. 2); трансфекционный титр также был максимален при использовании варианта $\mathrm{H} \triangle 18$, однако для варианта $4 \mathrm{~A}-\mathrm{H} \triangle 24$ полученный трансфекционный титр лишь незначительно уступал варианту $\mathrm{H} \Delta 18$, а для варианта $\mathrm{H} \triangle 24$ был, как минимум, на 2 порядка ниже, чем у варианта $\mathrm{H} \triangle 18$. В дальнейших опытах использовали лентивирусные частицы, псевдотипированные белками H $\triangle 18 / F \triangle 30$. При измерении на клетках HEK293 средний вирусный титр H/F-псевдотипированных лентивирусных препаратов был в 15-20 раз ниже, чем при псевдотипировании белком G вируса VSV (таблица).

\section{Оптимизация условий трансдукции клеток NK-92}

Использование VSV-G-псевдотипированных лентивирусных препаратов для трансдукции клеток NK-92 показало, что превышение титра $10^{5}$ и. е. на 1 мл среды в течение 8 ч приводит к существенному падению жизнеспособности культуры. Кроме того, клетки NK-92 гораздо менее эффективно трансдуцировались такими лентивирусами, различие в трансфекционном титре по сравнению с НЕК293 составляло более 3-х порядков. Для повышения эффективности трансдукции натуральных киллеров предложено применять ингибитор ТВК1/IKKع BX795 в концентрации 6-8 мкМ [20]. Оценка влияния ВХ795 на жизнеспособность клеток NK-92 показала, что они сохраняют жизнеспособность при концентрациях до 3 мкМ (рис. 3). Применение BX795 позволило снизить разницу в эффективности трансдукции VSV-G-псевдотипированными

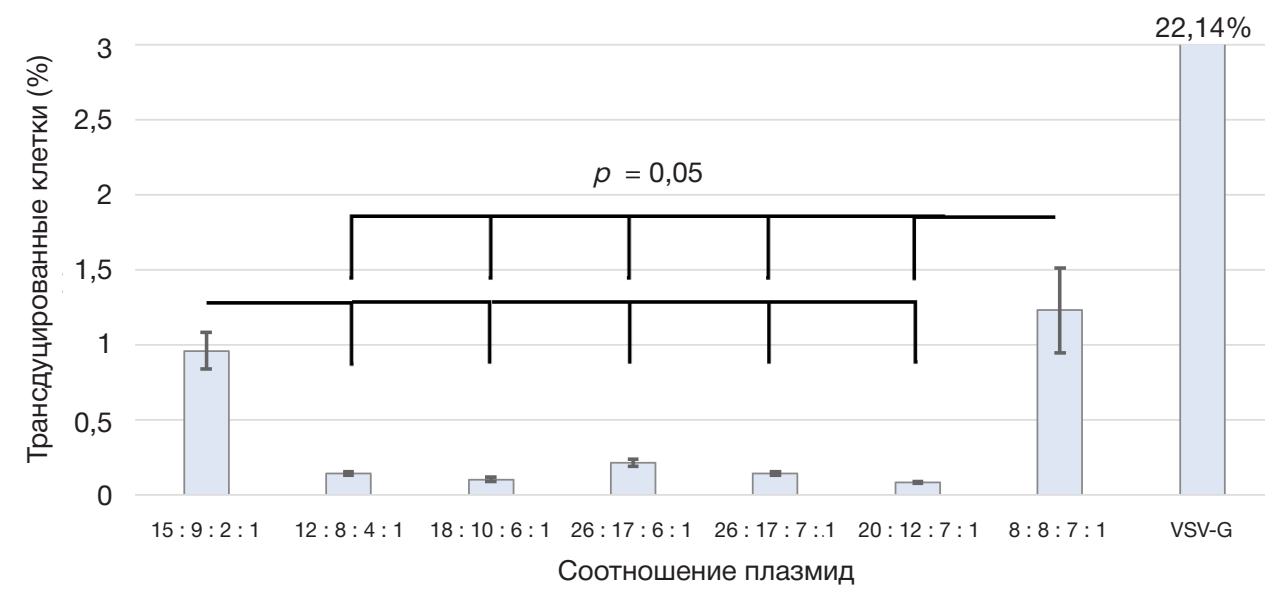

Рис. 1. Доля флуоресцирующих клеток HEK-293, оцененная через 48 ч после трансдукции клеточной популяции H/F-псевдотипированными и VSV-Gпсевдотипированными лентивирусными векторами. Ось X - соотношение плазмид вектор : psPAX2 : pMD2-F $\triangle 30$ : pCG-H $\triangle 18$

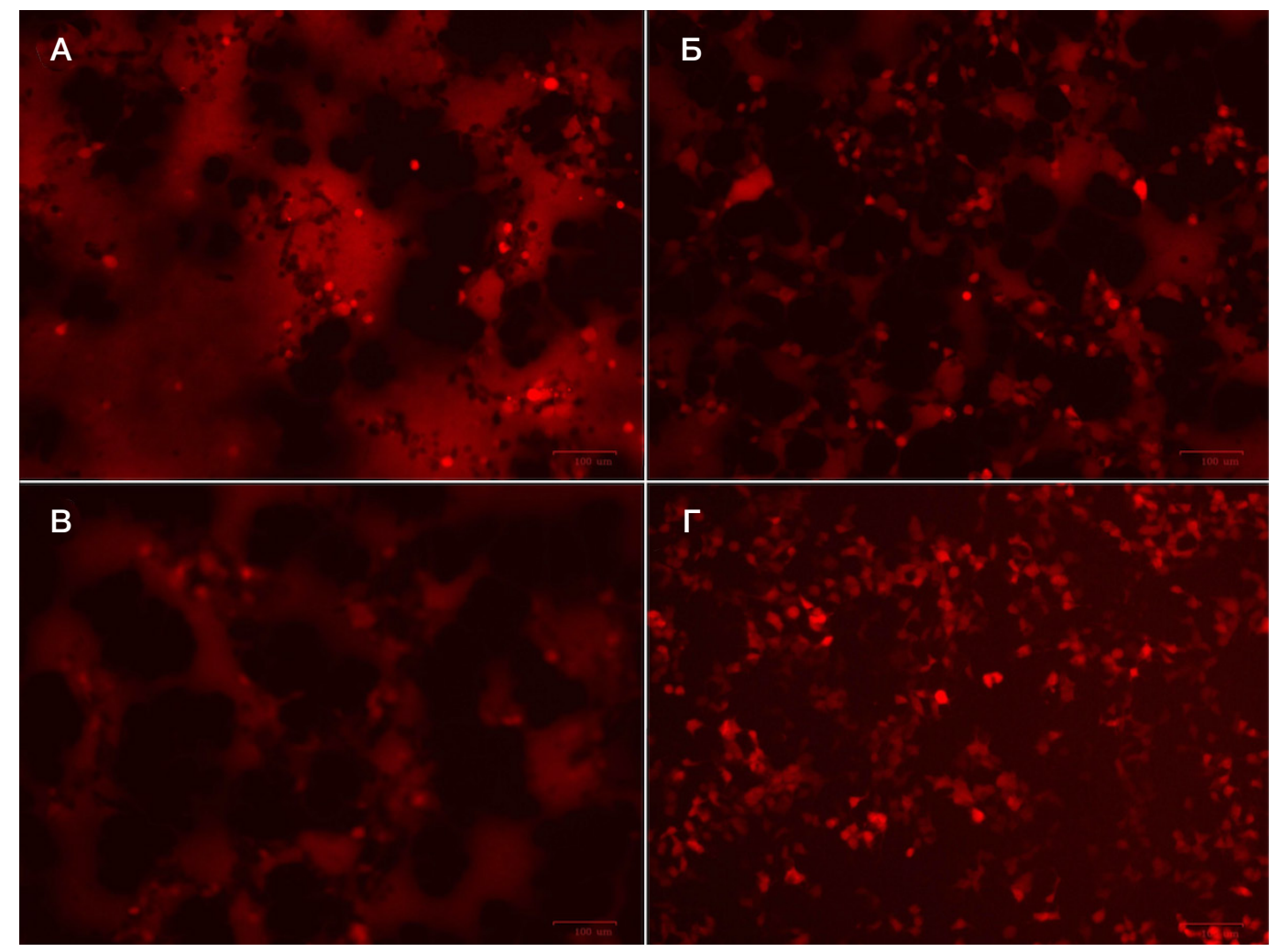

Рис. 2. Синцитии, образуемые клетками HEK-293Т после трансфекции смесью плазмид для продукции H/F-псевдотипированных лентивирусных частиц. A. pCG-Hc $\triangle 18+$ pMD2-F $\triangle 30$. Б. pCG-Hc $\triangle 24+$ pMD2-F $\triangle 30$. B. pCG-4A-Hc $\triangle 24+$ pMD2-F $\triangle 30$. Г. pMD2-G 
вирусными частицами в 300 раз. В тех же условиях трансдукции H/F-псевдотипированные лентивирусные препараты оказались способными трансдуцировать клетки NK-92 в три раза менее эффективно по сравнению с клетками НЕК-293.

\section{Оценка цитотоксического действия ХАР- трансдуцированных клеток NK-92}

Поскольку клетки NK-92 плохо поддаются культивации в низкой плотности, использованные величины соотношения клетка : инфекционная единица не позволяли получить достаточно высокую долю трансдуцированных клеток. Выделение фракции, экспрессирующей tagRFP, при помощи проточного сортировщика позволило получить небольшие фракции ХАР-экспрессирующих клеток, однако сопутствующий стресс приводил к существенной потере жизнеспособности. Для решения этой проблемы мы применили сортировку ХАР-экспрессирующих клеток при помощи магнитных частиц, покрытых моноклональными антителами к эпитопу DYKDDDDK. Такой подход оказался более щадящим и не приводил к подавлению пролиферации клеток NK-92. Полученные фракции ХАР-экспрессирующих клеток были протестированы на способность подавлять рост GFP-экспрессирующих CD20+ клеток Raji. По сравнению с немодифицированными клетками, @CD20-NK-92 оказались способны подавлять пролиферацию клеток Raji в меньшей дозе (рис. 4).

\section{ОБСУЖДЕНИЕ РЕЗУЛЬТАТОВ}

В ходе сравнения различных вариантов Н-гликопротеинов мы установили, что укорочение цитоплазматического домена более чем на 20 аминокислот нецелесообразно

Таблица. Титры инфекционных вирусных препаратов, полученных с применением различных вариантов Н-белка. Приведены значения, нормализованные на $10^{6}$ клеток-упаковщиков

\begin{tabular}{|l|c|c|}
\hline & HEK-293 & NK-92 \\
\hline $\mathrm{H} \triangle 18 / \mathrm{F} \Delta 30$ & $\sim 6,15 \cdot 10^{4}$ & $\sim 2,1 \cdot 10^{4}$ \\
\hline $\mathrm{H} \Delta 24 / \mathrm{F} \Delta 30$ & $<2 \cdot 10^{2}$ & $<2 \cdot 10^{2}$ \\
\hline $4 \mathrm{~A}-\mathrm{H} \Delta 24 / \mathrm{F} \Delta 30$ & $\sim 4,3 \cdot 10^{4}$ & $\sim 1,6 \cdot 10^{4}$ \\
\hline VSV-G & $\sim 1,1 \cdot 10^{6}$ & $\sim 3,5 \cdot 10^{3}$ \\
\hline
\end{tabular}

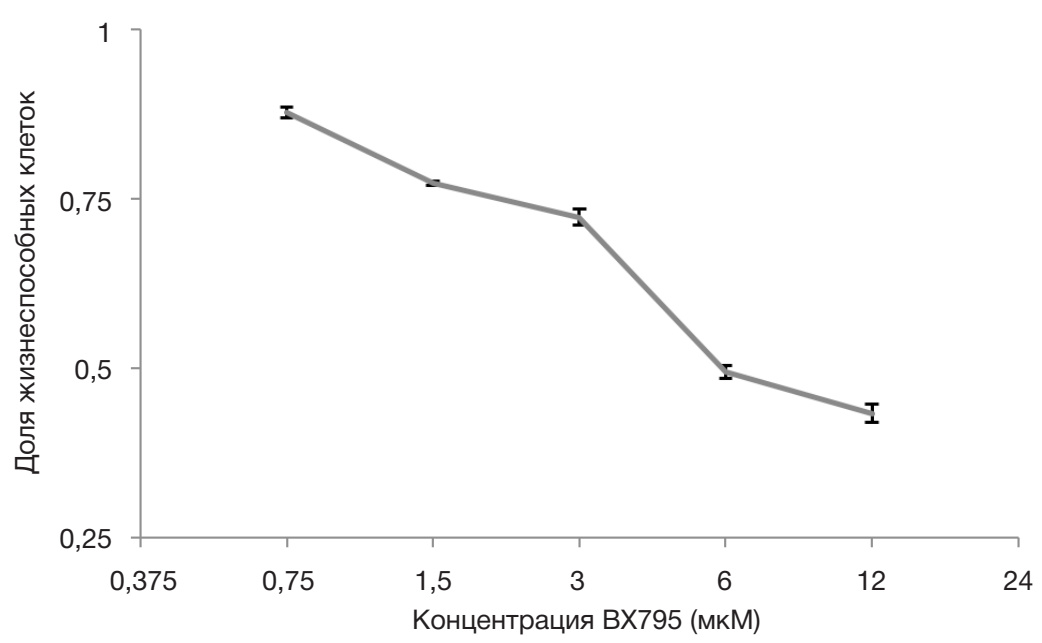

Рис. 3. Пролиферативная активность клеток NK-92, измеренная через 48 ч после добавления в питательную среду ВХ795 в различных концентрациях. Приведены значения, нормализованные относительно контрольных (необработанная культура). Значения ниже 0,5 характеризуют культуру, не пролиферировавшую с момента добавления препарата

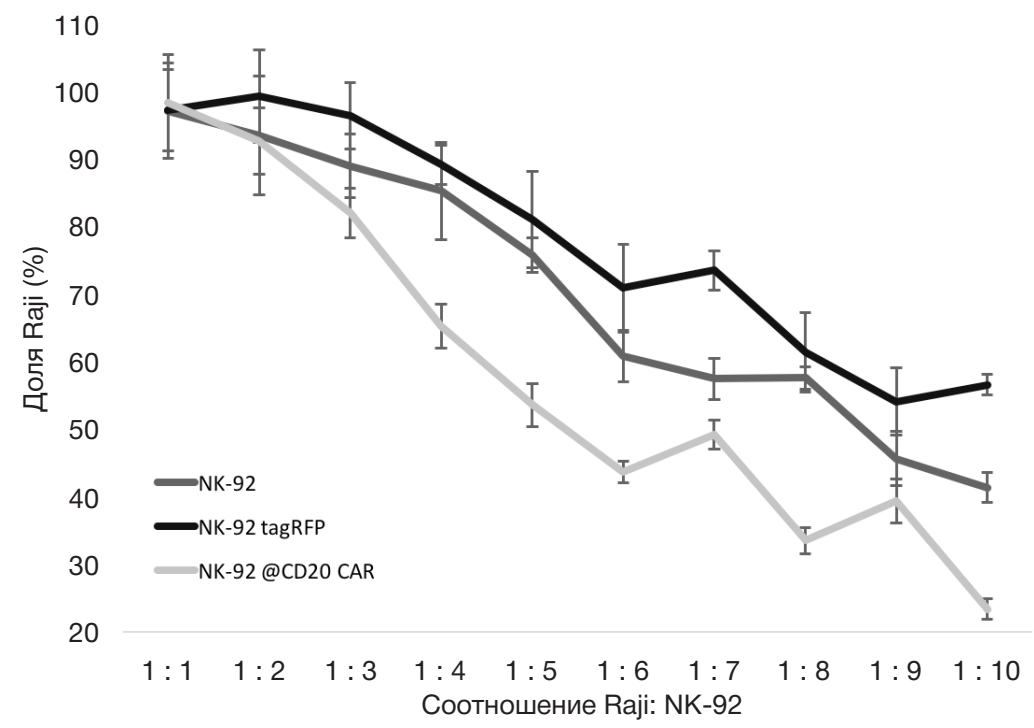

Рис. 4. Подавление пролиферации клеток линии Raji при кокультивировании с клетками NK-92. По шкале Y - процентная доля присутствовавших в образце клеток Raji с нормальным фенотипом (FSC/SSC) после двух дней совместного культивирования, относительно контрольного образца, в котором клетки Raji культивировались без клеток NK-92. Серии: нетрансдуцированные клетки NK-92; клетки NK-92, трансдуцированные экспрессором tagRFP (без селекции); клетки NK-92, трансдуцированные экспрессором XАP к CD20 и прошедшие селекцию 
ввиду сильного падения трансфекционного титра. H/F-псевдотипированные лентивирусные частицы отличались существенно меньшей эффективностью упаковки по сравнению с лентивирусными частицами, псевдотипированными белком VSV-G, однако этот фактор компенсировался большей эффективностью на обычно сложных для трансдукции клетках NK-92. В ходе экспериментов нами было отмечено, что обработка H/Fпсевдотипированными вирусными векторами приводит $\mathrm{K}$ менее значительному подавлению пролиферации клеток NK-92, позволяя использовать большие концентрации вирусных частиц для трансдукции и приводя $\mathrm{k}$ дополнительному повышению ее эффективности. Так же важно, что применительно к клеткам NK-92, ВX795 оказался активен во вдвое меньших дозах, чем при трансдукции первичных культур. В целом, использование сочетания H/F-псевдотипированных лентивирусных векторов, BX795 и последующей сортировки трансдуцированных фрракций на магнитных микросферах позволило нам стабильно получать популяции ХАР-экспрессирующих NK-92, демонстрирующие высокие уровни цитотоксичности против антиген-экспрессирующих клеток-мишеней.

Клетки NK-92 отличаются требовательностью к условиям культивирования и, как показали наши результаты, повышенной устойчивостью к трансдукции лентивирусными векторами. Однако сложности, связанные с получением ХАР-экспрессирующих клеток NK-92, в дальнейшем могут быть скомпенсированы большей универсальностью применения таких культур для клеточной иммунотерапии, либо в качестве компонентов комплексных терапевтических подходов, например в качестве клеточных носителей для доставки онколитических вирусов.

\section{ВЫВОДЫ}

Оптимальным вариантом белка H вируса кори для получения H/F-псевдотипированных лентивирусов является $\mathrm{H} \triangle 18$ (с точки зрения трансфекционного титра) и 4А-H $\triangle 24$ (с точки зрения продолжительности продукции вирусных частиц), наибольшие трансфекционные титры были достигнуты при использовании соотношения плазмид 8 : $8: 7: 1$. Полученные препараты H/F-псевдотипированных лентивирусных частиц обладали в 15-20 раз меньшим трансфекционным титром, по сравнению с VSV-Gпсевдотипированными, при этом разница в титрах при трансдукции клеток NK-92 достигала приблизительно соотношения 5 : 1 в пользу H/F-псевдотипированных частиц. Определена оптимальная концентрация ингибитора TBK1/IKKع ВX795, составившая 3 мкM; использование ВХ795 позволило почти в 3 раза повысить эффективность трансдукции. Трансдуцированные клетки ХAP-NK-92 были успешно изолированы путем связывания с компонентом химерного рецептора и отличались высокой способностью подавлять пролиферацию CD20+-клеток Raji.

\section{Литература}

1. Restifo NP, Dudley ME, Rosenberg SA. Adoptive immunotherapy for cancer: harnessing the T cell response. Nat Rev Immunol 2012; 12 (4): 269-81. DOI: 10.1038/nri3191. PubMed PMID: 22437939

2. Zah E, Lin MY, Silva-Benedict A, Jensen MC, Chen YY. T Cells Expressing CD19/CD20 Bispecific Chimeric Antigen Receptors Prevent Antigen Escape by Malignant B Cells. Cancer immunology research. 2016; 4 (6): 498-508. DOI: 10.1158/2326-6066.CIR15-0231. PubMed PMID: 27059623.

3. Olden BR, Cheng Y, Yu JL, Pun SH. Cationic polymers for nonviral gene delivery to human T cells. J Control Release. 2018; (282): 140-7. DOI: 10.1016/j.jconrel.2018.02.043. PubMed PMID: 29518467.

4. Zhang Z, Qiu S, Zhang X, Chen W. Optimized DNA electroporation for primary human T cell engineering. BMC Biotechnol. 2018; 18 (1): 4. DOI: 10.1186/s12896-018-0419-0. PubMed PMID: 29378552

5. Tumaini B, Lee DW, Lin T, Castiello L, Stroncek DF, Mackall C et al. Simplified process for the production of anti-CD19-CARengineered T cells. Cytotherapy. 2013; 15 (11): 1406-15. DOl: 10.1016/j.jcyt.2013.06.003. PubMed PMID: 23992830.

6. Yagita M, Huang CL, Umehara H, Matsuo Y, Tabata R, Miyake M et al. A novel natural killer cell line (KHYG-1) from a patient with aggressive natural killer cell leukemia carrying a p53 poin mutation. Leukemia. 2000; 14 (5): 922-30. PubMed PMID: 10803526.

7. Gong JH, Maki G, Klingemann HG. Characterization of a human cell line (NK-92) with phenotypical and functional characteristics of activated natural killer cells. Leukemia. 1994; 8 (4): 652-8. PubMed PMID: 8152260.

8. Matsuo Y, Drexler HG. Immunoprofiling of cell lines derived from natural killer-cell and natural killer-like T-cell leukemia-lymphoma Leuk Res. 2003; 27 (10): 935-45. PubMed PMID: 12860014.

9. Klingemann HG, Wong E, Maki G. A cytotoxic NK-cell line (NK92) for ex vivo purging of leukemia from blood. Biol Blood Marrow Transplant. 1996; 2 (2): 68-75. PubMed PMID: 9118301.

10. Zhang J, Sun R, Wei H, Zhang J, Tian Z. Characterization of interleukin-15 gene-modified human natural killer cells: implications for adoptive cellular immunotherapy. Haematologica. 2004; 89 (3): 338-47. PubMed PMID: 15020274.

11. Chen Y, You F, Jiang L, Li J, Zhu X, Bao Y et al. Gene-modified NK-92Ml cells expressing a chimeric CD16-BB-zeta or CD64BB-zeta receptor exhibit enhanced cancer-killing ability in combination with therapeutic antibody. Oncotarget. 2017; 8 (23): 37128-39. DOI: 10.18632/oncotarget.16201. PubMed PMID: 28415754 .

12. Suck G, Odendahl M, Nowakowska P, Seidl C, Wels WS, Klingemann HG et al. NK-92: an 'off-the-shelf therapeutic' for adoptive natural killer cell-based cancer immunotherapy. Cancer Immunol Immunother. 2016; 65 (4): 485-92. DOI: 10.1007/ s00262-015-1761-x. PubMed PMID: 26559813.

13. Boissel L, Betancur M, Lu W, Wels WS, Marino T, Van Etten RA et al. Comparison of mRNA and lentiviral based transfection of natural killer cells with chimeric antigen receptors recognizing lymphoid antigens. Leuk Lymphoma. 2012; 53 (5): 958-65. DOI: 10.3109/10428194.2011.634048. PubMed PMID: 22023526.

14. Humbert JM, Frecha C, Amirache Bouafia F, N'Guyen TH, Boni S, Cosset FL et al. Measles virus glycoprotein-pseudotyped lentiviral vectors are highly superior to vesicular stomatitis virus $G$ pseudotypes for genetic modification of monocyte-derived dendritic cells. J Virol. 2012; 86 (9): 5192-203. DOI: 10.1128/ JVI.06283-11. PubMed PMID: 22345444

15. Frecha C, Costa C, Negre D, Gauthier E, Russell SJ, Cosset FL et al. Stable transduction of quiescent T cells without induction of cycle progression by a novel lentiviral vector pseudotyped with measles virus glycoproteins. Blood. 2008; 112 (13): 4843-52. DOl: 10.1182/blood-2008-05-155945. PubMed PMID: 18812471.

16. Funke S, Maisner A, Muhlebach MD, Koehl U, Grez M, Cattaneo R et al. Targeted cell entry of lentiviral vectors. Mol Ther. 2008; 16 (8): 1427-36. DOI: 10.1038/mt.2008.128. PubMed PMID: 18578012

17. Kneissl S, Abel T, Rasbach A, Brynza J, Schneider-Schaulies J, 
Buchholz CJ. Measles virus glycoprotein-based lentiviral targeting vectors that avoid neutralizing antibodies. PLOS ONE. 2012; 7 (10): e46667. DOI: 10.1371/journal.pone.0046667. PubMed PMID: 23071609.

18. Ou W, Marino MP, Suzuki A, Joshi B, Husain SR, Maisner A et al. Specific targeting of human interleukin (IL)-13 receptor alpha2positive cells with lentiviral vectors displaying IL13. Human gene therapy methods. 2012; 23 (2): 137-47. DOI: 10.1089/ hgtb.2012.054. PubMed PMID: 22612657.
19. Marino MP, Panigaj M, Ou W, Manirarora J, Wei $\mathrm{CH}$, Reiser J. A scalable method to concentrate lentiviral vectors pseudotyped with measles virus glycoproteins. Gene Ther. 2015; 22 (3): 280-5. DOI: 10.1038/gt.2014.125. PubMed PMID: 25608718.

20. Sutlu T, Nystrom S, Gilljam M, Stellan B, Applequist SE, Alici E. Inhibition of intracellular antiviral defense mechanisms augments lentiviral transduction of human natural killer cells: implications for gene therapy. Hum Gene Ther. 2012; 23 (10): 1090-100. DOI: 10.1089/hum.2012.080. PubMed PMID: 22779406.

\section{References}

1. Restifo NP, Dudley ME, Rosenberg SA. Adoptive immunotherapy for cancer: harnessing the $T$ cell response. Nat Rev Immunol. 2012; 12 (4): 269-81. DOI: 10.1038/nri3191. PubMed PMID: 22437939

2. Zah E, Lin MY, Silva-Benedict A, Jensen MC, Chen YY. T Cells Expressing CD19/CD20 Bispecific Chimeric Antigen Receptors Prevent Antigen Escape by Malignant B Cells. Cancer immunology research. 2016; 4 (6): 498-508. DOI: 10.1158/2326-6066.CIR15-0231. PubMed PMID: 27059623.

3. Olden BR, Cheng Y, Yu JL, Pun SH. Cationic polymers for nonviral gene delivery to human T cells. J Control Release. 2018; (282): 140-7. DOI: 10.1016/j.jconrel.2018.02.043. PubMed PMID: 29518467

4. Zhang Z, Qiu S, Zhang X, Chen W. Optimized DNA electroporation for primary human T cell engineering. BMC Biotechnol. 2018; 18 (1): 4. DOI: 10.1186/s12896-018-0419-0. PubMed PMID: 29378552.

5. Tumaini B, Lee DW, Lin T, Castiello L, Stroncek DF, Mackall C et al. Simplified process for the production of anti-CD19-CARengineered T cells. Cytotherapy. 2013; 15 (11): 1406-15. DOI: 10.1016/j.jcyt.2013.06.003. PubMed PMID: 23992830.

6. Yagita M, Huang $\mathrm{CL}$, Umehara $\mathrm{H}$, Matsuo $\mathrm{Y}$, Tabata R, Miyake $\mathrm{M}$ et al. A novel natural killer cell line (KHYG-1) from a patient with aggressive natural killer cell leukemia carrying a p53 point mutation. Leukemia. 2000; 14 (5): 922-30. PubMed PMID: 10803526

7. Gong JH, Maki G, Klingemann HG. Characterization of a human cell line (NK-92) with phenotypical and functional characteristics of activated natural killer cells. Leukemia. 1994; 8 (4): 652-8. PubMed PMID: 8152260.

8. Matsuo Y, Drexler HG. Immunoprofiling of cell lines derived from natural killer-cell and natural killer-like T-cell leukemia-lymphoma. Leuk Res. 2003; 27 (10): 935-45. PubMed PMID: 12860014

9. Klingemann HG, Wong E, Maki G. A cytotoxic NK-cell line (NK92) for ex vivo purging of leukemia from blood. Biol Blood Marrow Transplant. 1996; 2 (2): 68-75. PubMed PMID: 9118301.

10. Zhang J, Sun R, Wei H, Zhang J, Tian Z. Characterization of interleukin-15 gene-modified human natural killer cells: implications for adoptive cellular immunotherapy. Haematologica. 2004; 89 (3): 338-47. PubMed PMID: 15020274

11. Chen Y, You F, Jiang L, Li J, Zhu X, Bao Y et al. Gene-modified NK-92Ml cells expressing a chimeric CD16-BB-zeta or CD64BB-zeta receptor exhibit enhanced cancer-killing ability in combination with therapeutic antibody. Oncotarget. 2017; 8 (23): 37128-39. DOI: 10.18632/oncotarget.16201. PubMed PMID: 28415754.
12. Suck G, Odendahl M, Nowakowska P, Seidl C, Wels WS Klingemann HG et al. NK-92: an 'off-the-shelf therapeutic' for adoptive natural killer cell-based cancer immunotherapy. Cancer Immunol Immunother. 2016; 65 (4): 485-92. DOI: 10.1007/ s00262-015-1761-x. PubMed PMID: 26559813.

13. Boissel L, Betancur M, Lu W, Wels WS, Marino T, Van Etten RA et al. Comparison of mRNA and lentiviral based transfection of natural killer cells with chimeric antigen receptors recognizing lymphoid antigens. Leuk Lymphoma. 2012; 53 (5): 958-65. DOI: 10.3109/10428194.2011.634048. PubMed PMID: 22023526.

14. Humbert JM, Frecha C, Amirache Bouafia F, N'Guyen TH, Boni S, Cosset FL et al. Measles virus glycoprotein-pseudotyped lentiviral vectors are highly superior to vesicular stomatitis virus G pseudotypes for genetic modification of monocyte-derived dendritic cells. J Virol. 2012; 86 (9): 5192-203. DOI: 10.1128/ JVI.06283-11. PubMed PMID: 22345444.

15. Frecha C, Costa C, Negre D, Gauthier E, Russell SJ, Cosset FL et al. Stable transduction of quiescent $T$ cells without induction of cycle progression by a novel lentiviral vector pseudotyped with measles virus glycoproteins. Blood. 2008; 112 (13): 4843-52. DOI: 10.1182/blood-2008-05-155945. PubMed PMID: 18812471

16. Funke S, Maisner A, Muhlebach MD, Koehl U, Grez M, Cattaneo R et al. Targeted cell entry of lentiviral vectors. Mol Ther. 2008; 16 (8): 1427-36. DOI: 10.1038/mt.2008.128. PubMed PMID: 18578012 .

17. Kneissl S, Abel T, Rasbach A, Brynza J, Schneider-Schaulies J, Buchholz CJ. Measles virus glycoprotein-based lentiviral targeting vectors that avoid neutralizing antibodies. PLoS ONE. 2012; 7 (10): e46667. DOI: 10.1371/journal.pone.0046667. PubMed PMID: 23071609

18. Ou W, Marino MP, Suzuki A, Joshi B, Husain SR, Maisner A et al, Specific targeting of human interleukin (IL)-13 receptor alpha2positive cells with lentiviral vectors displaying IL13. Human gene therapy methods. 2012; 23 (2): 137-47. DOI: 10.1089/ hgtb.2012.054. PubMed PMID: 22612657.

19. Marino MP, Panigaj M, Ou W, Manirarora J, Wei CH, Reiser J. A scalable method to concentrate lentiviral vectors pseudotyped with measles virus glycoproteins. Gene Ther. 2015; 22 (3): 280-5. DOI: 10.1038/gt.2014.125. PubMed PMID: 25608718.

20. Sutlu T, Nystrom S, Gilljam M, Stellan B, Applequist SE, Alici E. Inhibition of intracellular antiviral defense mechanisms augments lentiviral transduction of human natural killer cells: implications for gene therapy. Hum Gene Ther. 2012; 23 (10): 1090-100. DOI: 10.1089/hum.2012.080. PubMed PMID: 22779406. 